\title{
IbM PELATIHAN, PEMBINAAN DAN PENDAMPINGAN BIDANG KERAJINAN, SOUVENIR, SABLON DAN PERCETAKAN
}

\author{
Ismail $^{1 *}$, Jhony Syafwandhinata ${ }^{2}$ \\ ${ }_{1,2}$ AMIK Indonesia \\ *E-mail: ismail@amikindonesia.ac.id
}

\begin{abstract}
ABSTRAK
Upaya yang efektif dan komprehensif membutuhkan partisipasi banyak pihak demi meningkatkan kualitas dan kewirausahaan bagi kalangan pemuda agar terhindarnya perilaku negatif dalam lingkungan seperti narkoba, criminal, dan sebagainya. Pendidikan formal belum cukup untuk membentuk kewirausahaan, kurikulum di lembaga pendidikan belum sepenuhnya dimiliki Perguruan Tinggi dalam menciptakan wirausahawan baru. Perguruan Tinggi memiliki kewajiban dalam melakukan pengembangan pendidikan sebagai bentuk partisipasinya dalam mendukung usahawan muda di daerah sekitar. Salah satu upaya untuk mendorong wirausahawan dalah dengan memberikan pelatihan, pembinaan, dan pendampingan. Kegiatan IbM dilakukan pada kelompok usaha muda di Banda Aceh dilakukan pada bulan juli tahun 2017. Metode pelaksanaan program yang akan dilakukan adalah : (1) pelatihan manajemen usaha, (2) Pelatihan produksi, (3) pelatihan administrasi dan (4) pendampingan. Semua metode ini merupakan satu kesatuan dari program IbM. Hasil dari kegiatan IbM ini telah membentuk kerjasama dan pengetahuan serta keahlian bagi peserta sehingga mampu dalam mengelola usaha bidang kerajinan, souvenir, sablon dan percetakan.
\end{abstract}

Kata kunci: IbM, pelatihan, pembinaan, pendampingan, kerajinan, souvenir, sablon dan percetakan.

\section{TRAINING, COACHING, AND ASSISTANCE OF CRAFTS, SOUVENIRS, SCREEN PRINTING AND PRINTING}

\begin{abstract}
An effective and comprehensive effort requires the participation of many parties in order to improve the quality and entrepreneurship of young people to avoid negative behavior in the environment such as drugs, crime, and so on. Formal education is not enough to form entrepreneurship, the curriculum in educational institutions is not yet fully owned by universities in creating new entrepreneurs. Higher Education has an obligation to carry out educational development as a form of participation in supporting young entrepreneurs in the surrounding area. One effort to encourage entrepreneurs is to provide training, coaching, and mentoring. IbM activities carried out on young business groups in Banda Aceh carried out in July 2017. The method of implementing the program will be carried out: (1) business management training, (2) production training, (3) administrative training, and (4) mentoring. All of these methods are an integral part of the IbM program. The results of this IbM activity have formed collaboration and knowledge and expertise for participants so they are able to manage businesses in the field of crafts, souvenirs, screen printing and printing.
\end{abstract}

Keywords: IbM, training, coaching, mentoring, crafts, souvenirs, screen printing, and printing

\section{PENDAHULUAN}

Upaya yang efektif dan komprehensif membutuhkan partisipasi banyak pihak [1], tidak terkecuali pemuda sebagai generasi penerus bangsa [2,3]. Alasan kuat mengapa pemuda perlu dilibatkan, karena pemuda berperan dalam menjadi pelopor perubahan dari jaman penjajahan sampai era reformasi, oleh karena itu peran pemuda secara aktif dalam mengatasi permasalahan melalui tindakan pencegahan sangat diperlukan [4,5]. Ketika peran aktif dari berbagai pihak mendukung kegiatan pemuda telah solid dan kuat, maka harapannya masalah-masalah negatif dalam lingkungan seperti narkoba, kriminal, pelecahan dapat diatasi dengan baik [6,7].

Pentingnya peran pemuda dalam pembangunan karena dianggap berada dalam usia yang produktif untuk menunjang berbagai aktivitas pembangunan di berbagai sektor [8,7]. Program dan pelatihan dibutuhkan untuk dapat menunjang pemberdayaan pemuda agar lebih produktif dalam berbagai bidang $[9,10]$. Sebagian pemuda memiliki kesempatan untuk mengenyam pendidikan tinggi 
dan memperoleh bekal di masa depan [11], sebagian lagi menghadapi kenyataan tidak mengenyam pendidikan tinggi atau bahkan putus sekolah [12]. Sebagian pemuda dapat diserap di pasar tenaga kerja $[13,8]$, dan sebagian lagi tersisih dari persaingan dan menjadi kelompok yang statis $[8,13,14]$. Sebagian kecil pemuda memulai membuat bisnis dari usaha yang bermodal kecil hingga sampai besar $[15,16,17]$, mayoritas pemuda lebih memilih menjadi tenaga kerja formal dibandingkan terjun dalam bidang kewirausahaan [18]. Kondisi ini mengakibatkan terjadinya kelompok pengangguran pada usia produktif [19].

Pendidikan formal belum cukup untuk membentuk kewirausahaan [20], kurikulum di lembaga pendidikan belum sepenuhnya dimiliki Perguruan Tinggi dalam menciptakan wirausahawan baru [21, 22], atau dalam membangun kemandirian pemuda melalui kegiatan wirausaha [23]. Pemerintah telah mengupayakan pemberdayaan kewirausahaan pemuda dengan melibatkan berbagai pihak seperti Kementrian Pemuda dan Olahraga [24], Ditjen PNFI [25], Perguruan Tinggi termasuk BUMN untuk memfasilitasi pelatihan dan pembiayaan [26]. Dengan harapan terciptanya sinergitas antar berbagai pihak dalam mendorong pengembangan kewirausahaan pemuda [27, 28]. Seiring dengan perkembangannya, Perguruan Tinggi AMIK Indonesia telah melakukan pengembangan usaha pada bidang-bidang lainnya sebagai bentuk partisipasinya dalam mendukung usahawan muda di daerah sekitar. Sampai saat ini, pengusaha Peugot Aceh telah berhasil mengembangkan usaha pada bidang percetakan dan sablon seperti, pembuatan spanduk, kartu undangan, kartu nama, nota, kuitansi dan lain-lain yang dalam pengerjaannya masih dilakukan secara manual dan fasilitas seadanya, sedangkan prospek dari usaha itu sendiri sangat menjanjikan.

Keterampilan yang dimiliki oleh personil kelompok usaha sudah mencukupi untuk pengembangan yang lebih kepada usaha bisnis yang lebih besar. Akan tetapi, seperti halnya lain kelompok usaha di tempat lain, permasalahan utama yang sering muncul adalah yang berkaitan dengan aspek bisnis seperti manajemen bisnis yang masih tradisional. Kondisi usaha yang dialami oleh kelompok usaha ini memerlukan sentuhan dari pihak lain agar terjadi pengembangan usaha yang signifikan. Program Ipteks bagi Masyarakat $(\mathrm{IbM})$ yang telah diselenggarakan berdasarkan latar belakang di atas serta fokus permasalahan yang akan diprioritaskan untuk dipecahkan dalam kegiatan IbM tersebut. Berdasarkan latar belakang tersebut, program IbM ini dinamakan "IbM Usaha Peugot Aceh Bidang Kerajinan, Souvenir, Sablon dan Percetakan.

Kelompok usaha "Peugot Aceh" telah berjalan selama 6 Tahun lebih. Sebagaimana halnya kelompok usaha yang berkarakter dinamis, kelompok usaha ini telah berperan dalam pengembangan diri pemuda melalui kegiatan kewirausahaan. Perannya telah dirasakan tidak hanya oleh pemuda sendiri tetapi oleh masyarakat sekitar karena berhasil dalam menciptakan aktivitas yang produktif bagi para pemuda. Di sisi lain dapat memutus mata rantai kegiatan negatif pemuda pada periode sebelumnya dan disamping menjadi role model bagi angkatan berikutnya.

Berikut ini adalah hasil identifikasi kami terhadap permasalahan yang dihadapi dan harus dipecahkan oleh kelompok usaha dilihat dari berbagai sudut pandang yang relevan.

a. Belum adanya perencanaan bisnis yang jelas sehingga target dan sasaran usaha belum memiliki arah kepada pengembangan usaha bisnis yang lebih mapan.

b. Manajemen keuangan yang belum memenuhi standar akuntansi dan masih belum terdigitalisasi sehingga belum ada manajemen yang baik.

c. Pengelolaan produksi yang berorientasi pada pesanan bukan pada persediaan. Hal ini menyebabkan lemahnya fungsi pemasaran. Kelompok usaha tidak memiliki strategi pemasaran, hal ini bisa diakibatkan belum mantapnya perencanaan bisnis.

d. Beberapa keterampilan produksi dari ragam usaha sablon dan percetakan ini sudah dikuasai oleh beberapa personil. Akan tetapi, keterampilan sablon dan percetakan masih manual karena minimnya alat-alat yang tersedia. Disamping modal yang tidak tersedia, keterampilan produksi dengan alat yang lebih canggih belum banyak dikuasai.

e. Kurangnya permodalan untuk ekspansi usaha. Hal ini disebabkan oleh lemahnya networking dengan instansi atau lembaga terkait baik lembaga pemerintah atau swasta.

f. Masih kurangnya motivasi bisnis untuk pengembangan usaha. Hal ini berakibat kegiatan usaha berjalan secara stagnan tanpa ada upaya untuk pengembangan skala usaha yang lebih besar. 
BAKTI BANUA : Jurnal Pengabdian Kepada Masyarakat

Volume 1 No. 1 Mei 2020

https://ejurnal.stimi-bjm.ac.id/index.php/BBJM/

g. Belum memiliki basecame tempat usaha yang tetap, karena masih menyewa. Hal ini sering mengganggu dalam kegiatan usaha produksi

\section{Tujuan Pengabdian Kepada Masyarakat}

Berdasarkan analisis masalah di atas, maka tujuan pelaksanaaan IbM adalah :

a. Meningkatkan motivasi berwirausaha mitra baik secara individu maupun secara kelompok;

b. Meningkatkan pemahaman mitra tentang manajemen usaha terutama yang berkaitan dengan optimalisasi manajemen sumber daya manusia. Mitra memiliki pengetahuan tentang model pembagian tugas dan kewenangan dalam menjalankan usaha bisnis;

c. Meningkatkan pemahaman mitra tentang rumusan dan manfaat perencanaan bisnis (bussines plan) serta dihasilkan dokumen perencanaan bisnis sebagai rencana pengembangan usaha baik dalam jangka pendek, jangka menengah dan jangka panjang;

d. Meningkatkan pemahaman mitra tentang manajemen keuangan. Sebagai bentuk keluarannya adalah laporan keuangan usaha yang lengkap dalam kurun waktu 5 bulan masa kerjasama kegiatan IbM;

e. Meningkatkan keterampilan anggota mitra dalam menggunakan komputer terutama dalam memanfaatkan software-software untuk keperluan desain kreatif serta penggunaan internet untuk media promosi. Sebagai bentuk produk keluarannya adalah dihasilkan beberapa disain kreatif untuk pembuatan kaos dengan tema yang relevan dengan program pemerintah daerah seperti pendidikan, kesehatan, lingkungan atau parawisata. Juga dihasilkan blog untuk media promosi yang lebih komprehensif dan intensif untuk kegiatan pemasaran;

f. Mengembangkan model kaos dengan desain kreatif yang siap dipasarkan serta model-model souvenir dan kerajinan yang memiliki nilai jual yang tinggi;

g. Meningkatkan pemahaman dan keterampilan mitra tentang proses produksi dengan menggunakan alat yang lebih canggih seperti sablon kaos dan cetak dijital. Dihasilkan contoh produk souvenir, kerajinan, kaos atau hasil cetak seperti undangan dan lain-lain. Produk ini bukan hanya sampel saja tetapi siap untuk dipasarkan;

h. Meningkatkan pemahaman dan keterampilan dalam membuat media promosi dan strategi pemasaran. Dihasilkan model media promosi baik cetak maupun media di internet;

i. Meningkatkan pemahaman dan keterampilan mitra dalam mengembangkan jaringan usaha baik untuk kepentingan pendanaan, produksi maupun pemasaran. Terjalinnya beberapa kesepakatan kerjasama dengan pihak lain;

j. Menghasilkan proposal untuk diajukan memperoleh dana dari pemerintah maupun dari swasta baik berupa hibah, seperti program kelompok usaha pemuda produktif (kupp) dan kelompok wirausaha desa (kwd) dari ditjen fnpi serta dari pemerintah daerah atau berupa pendanaan dalam bentuk kredit dari perbankan maupun dari bumn non bank;

k. Meningkatkan peran kelompok usaha "Peugot Aceh" sebagai pusat kegiatan kewirausahaan pemuda minimal untuk tingkat kelurahan; serta

1. Mengembangkan rancangan koperasi untuk mewadahi dan menopang kegiatan kewirausahaan pemuda.

\section{Manfaat Pengabdian Kepada Masyarakat}

Bagi usaha Peugot Aceh yang diselenggarakan di Akademi Manajemen Informatika dan Komputer (AMIK) Indonesia pelatihan ini diharapkan akan dapat :

a. Meningkatkan jiwa entrepreneurship usaha Peugot Aceh sebagai upaya menunjang kegiatan pengembangan kelompok;

b. Usaha Peugot Aceh memiliki kemampuan perencanaan bisnis;

c. Meningkatnya kemampuan usaha Peugot Aceh dalam melakukan operasional bisnis;

d. Bertambahnya jaringan kerjasama bisnis;

e. Model kelompok usaha pemuda "Peugot Aceh" dijadikan model pengembangan wirausaha pemuda yang berbasis pemberdayaan masyakarat; serta

f. Mampu meningkatkan partisipasi dosen dan mahasiswa Akademi Manajemen Informatika dan Komputer (AMIK) Indonesia dalam kegiatan pemberdayaan masyarakat 
BAKTI BANUA : Jurnal Pengabdian Kepada Masyarakat

Volume 1 No. 1 Mei 2020

https://ejurnal.stimi-bjm.ac.id/index.php/BBJM/

\section{METODE}

\section{Lokasi Pengabdian}

Lokasi pengabdian ini pada Usaha Peugot Aceh dan dilaksanakan pada tanggal 3 Juli 2017.

\section{Ruang Lingkup Pengabdian}

Adapun ruang lingkup utama dari kegiatan pengabdian kepada masyarakat ini adalah untuk memberikan pengetahuan dan meningkatkan kemampuan bagi Peugot Aceh dalam hal pelatihan, pembinaan dan pendampingan bidang kerajinan, souvenir, sablon dan percetakan.

\section{Kelompok Sasaran}

Pelatihan ini difokuskan kepada Peugot Aceh dan peserta sebanyak 10 peserta.

\section{Prosedur Kegiatan}

Melalui kegiatan IbM ini akan ditawarkan solusi bagi permasalahan-permasalahan yang telah dirumuskan di atas. Pendekatan yang ditawarkan bagi realisasi program IbM ini adalah model pemberdayaan dengan langkah-langkah sebagai berikut : 1) Tahap Persiapan; 2) Tahap Assesment; 3) Tahap Perencanaan Alternatif Program atau Kegiatan; 4) Tahap Pemformulasian Rencana Aksi; 5) Tahap Pelaksanaan (Implementasi) Program atau Kegiatan; 6) Tahap Evaluasi; serta 7) Tahap Terminasi. Pelaksanaan program IbM ini memang dilaksanakan sebagai upaya pemberdayaan kelompok pemuda dalam bidang kewirausahaan melalui kegiatan pelatihan kewirausahaan yang menitikberatkan kepada pengembangan usaha. Metode pelaksanaan program yang akan dilakukan adalah : (1) pelatihan manajemen usaha, (2) Pelatihan produksi, (3) pelatihan administrasi dan (4) pendampingan. Semua metode ini merupakan satu kesatuan dari program IbM ini.

\section{HASIL DAN PEMBAHASAN \\ Motivasi wirausaha}

Motivitasi umum yang dimiliki oleh personil usaha Aceh Peugot adalah ingin memiliki penghasilan. Berawal dari kumpulan pemuda terbentuklah kelompok usaha Aceh Peugot yang pada awal bergerak pada bidang pembuatan souvenir serta barang-barang kerajinan cindera mata. Untuk menjadikan usaha yang lebih matang dan besar tidak hanya cukup memiliki motif untuk memperoleh penghasilan karena itu akan menjebak kelompok usaha dalam putaran bisnis yang tidak berkembang. Kegiatan awal yang dilakukan untuk menyentuh aspek motivasi usaha yang dilakukan adalah kegiatan taining wirausaha untuk materi motivasi wirausaha. Kegiatan ini dilaksanakan pada hari tanggal 3 Juli 2017 di Aula pertemuan AMIK Indonesia. Kegiatan ini dilakukan dalam bentuk pelatihan motivasi wirausaha dalam bentuk tukar pengalaman dengan usahawan muda yang sukses untuk meningkatkan gairah wirausaha pemuda mitra. Pemateri yang diundang pada kegiatan ini adalah seorang Pengusana Muda dari Aceh yang bernama Abdurrazak yang memiliki usaha dalam bidang konveksi dan sablon di daerah Banda Aceh. Kegiatan ini dihadiri oleh semua personil mitra dan pihak usaha pemuda yang berada di daerah setempat.

\section{Manajemen kelembagaan dan personalia}

Seperti halnya kelompok usaha kecil dan menengah, faktor individu masih dianggap menonjol dalam mementukan model kelembagaan dan pengaturan personalia. Walaupun jumlah personil ada 10 orang, tetapi hanya 4 orang yang dianggap mengendalikan usaha ini. Pembagian tugas didasarkan kepada kemampuan masing-masing. Namun dengan kemampuan yang dimiliki oleh 4 orang ini, proses produksi percetakan dan sablon bisa dikuasai. Hal ini bisa diatasi jika produk yang dikembangkan tidak banyak dan tidak didesak oleh waktu, tetapi jika produk yang dikembangkan cukup kompleks dan banyak serta waktu pengerjaan sesuai dengan pesanan pada waktu yang mendesak, maka biasa menggunakan tenaga luar atau personil yang kurang aktif untuk membantu menyelesaikan proses produksi. Selama kegiatan IbM berlangsung, dilakukan rasionalisasi tugas dan tanggung jawab masing-masing personil agar proses produksi bisa lebih baik. Serta dirancang model tugas pekerjaan yang dapat dilakukan oleh setiap personil bahkan bagi siapapun yang terlibat dalam 
BAKTI BANUA : Jurnal Pengabdian Kepada Masyarakat

Volume 1 No. 1 Mei 2020

https://ejurnal.stimi-bjm.ac.id/index.php/BBJM/

proses produksi secara tentatif sesuai kebutuhan. Hal ini penting dilakukan agar proses produksi terjamin kualitasnya

\section{Manajemen produksi}

Keterampilan produksi yang dimiliki oleh personil dianggap cukup menunjang terhadap proses produksi percetakan, souvenir dan sablon. Keterampilan tersebut diperoleh secara otodidak yang dikembangkan secara bertahap oleh kelompok usaha. Semua personil dapat melakukan proses produksi kecuali kemampuan disain perancangan produk yang hanya dimiliki oleh dua orang. Alat dan bahan produksi tidak menjadi masalah karena akses terhadap barang dan alat produksi sudah bisa di akses di Banda Aceh, Hanya saja sering terjadi kesulitan jika alat-alat utama tidak bekerja dengan baik seperti komputer dan printer untuk perancangan atau desain produk. Teknik produksi dasar sudah dikuasai oleh semua personil yang ada. Namun hal ini belumlah dianggap cukup untuk pengembangan kualitas produk yang lebih baik dengan standar pasar yang lebih tinggi. Salah satu kegiatan untuk meningkatkan kemampuan teknik produksi personil adalah mengunjungi beberapa sentra produksi cetak sablon yang merupakan sentra produksi sablon dengan kelas Distro di Aceh pada tanggal 3 Juli 2017. Selama di Aceh mereka memperoleh pelatihan yang tentang teknik produksi yang tinggi baik untuk pekerjaan kecil maupun pekerjaan partai.

\section{Manajemen keuangan}

Berkaitan dengan manajemen keuangan, ada empat aspek yang perlu diperhatikan yaitu sumber pendanaan, perencanaan keuangan, manajemen pemasukan dan pengeluaran. Pengembangan manajemen keuangan diarahkan agar agar kelompok usaha memiliki sistem pengelolan keuangan yang standar sehingga bisa dijadikan dasar pendanaan kepada pihak lain.

Selama ini, ada beberapa sumber pendanaan yang digunakan, yiatu bank, dana PNPM serta modal sendiri yang dikembangkan. Karena produksi lebih menitikberatkan kepada barang-barang berdasarkan pesanan, maka sumber pendanaan dari pihak bank dan sumber dan luar lainnya tidak diperlukan. Laporan keuangan yang tersedia memang baru laporan kas. Selama kegiatan IbM, mereka dilatih untuk dapat meningkatkan kemampuan manajemen keuangan dengan tujuan agar manajemen keuangan yang baik dapat menunjang produktivitas usaha.

\section{Manajemen pemasaran}

Selama kegiatan IbM, kelompok usaha bisnis telah didorong untuk mulai membuka diri untuk melakukan promosi lebih intensif dengan mengembangkan media promosi seperti brosur yang disebarkan kepada target pelanggan seperti instansi, sekolah atau melalui pelanggan yang telah ada. Untuk pemasaran produk sablon dan percetakan dianggap sudah cukup baik karena telah lama dikenal sebagai sentra percetakan dan sablon. Namun untuk produk handycraft, pemasaran dianggap belum berjalan dengan baik. Sehingga dalam beberapa tahun ini, proses pemasaran handycraft lebih diarahkan untuk pemenuhan kebutuhan souvenir pernikahan.
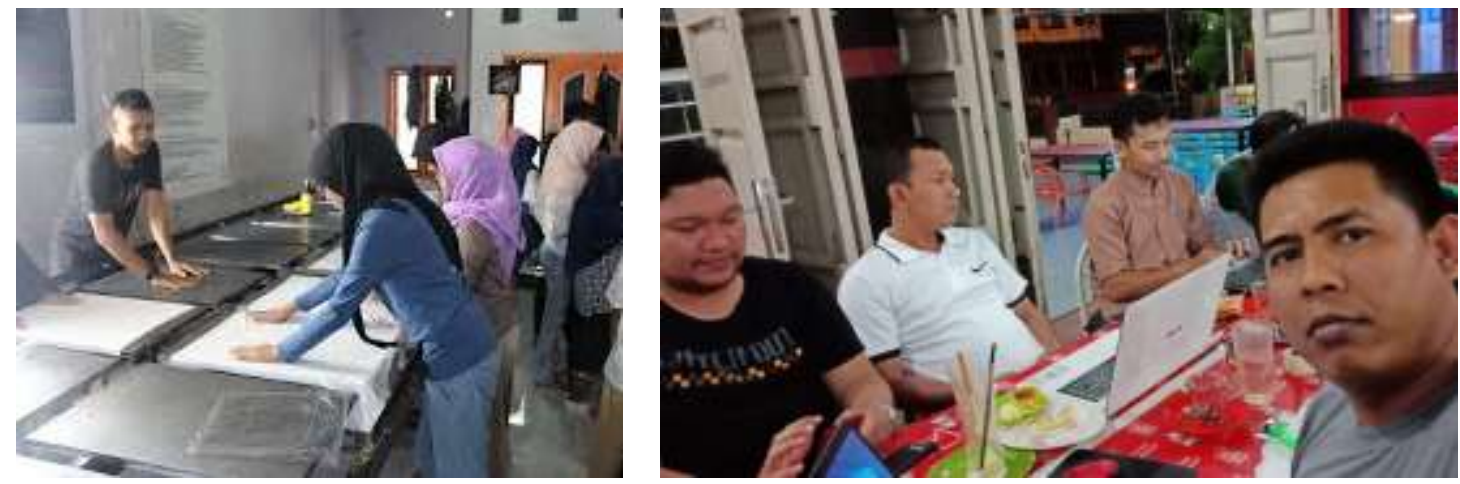

Gambar 1. Kegiatan Pelaksanaan Pelatihan dan Rapat Anggota Tim 


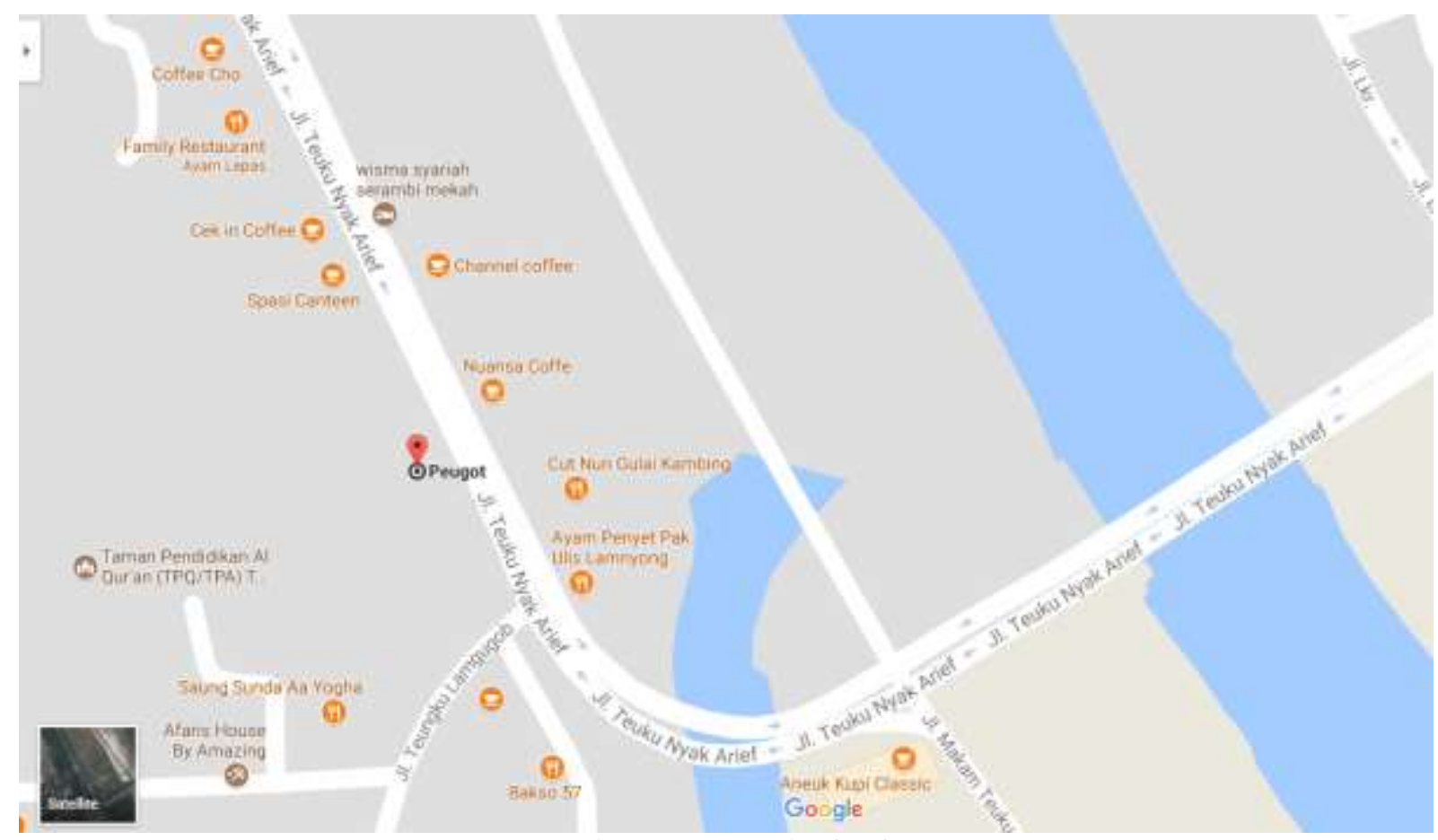

Gambar 2. Peta Lokasi Mitra

\section{SIMPULAN}

Berdaasarkan laporan kegiatan yang telah dipaparkan, berikut ini beberapa kesimpulan yang bisa dihasilkan.

a. Kegiatan pelatihan motivasi wirausaha mampu meningkatkan jiwa entrepreneurship para pemuda sebagai upaya menunjang kegiatan pengembangan kelompok usaha "Peugot Aceh" bidang usaha sablon dan percetakan serta pemuda yang lainnya.

b. Kegiatan pendampingan untuk membuat perencanaan bisnis kelompok usaha "Peugot Aceh" telah mampu mengembangkan kemampuan mereka untuk melakukan perencanaan bisnis tersebut.

c. Kegiatan IbM meliputi pelatihan dan pendampingan telah meningkatkan kemampuan kelompok usaha "Peugot Aceh" dalam melakukan operasional bisnisnya sesuai dengan jenis usaha yang dijalankan.

d. Kegiatan pendampingan dalam mengelola keuangan telah meningkatkan kualitas pengelolaan keuangan.

e. Kegiatan promosi dan pengembangan jaringan pemasaran telah dijadikan sebagai strategi pemasaran untuk meningkatkan volume produksi kelompok usaha "Peugot Aceh".

f. Pengembangan networking dengan pihak lain untuk membangun kerjasama bisnis telah dilakukan untuk peningkatan pemasaran dan pendanaan.

g. Pelatihan produksi melalui kunjungan ke sentra-sentra produksi di percetakan dan kaos di Bandung telah mampu meningkatkan pengetahuan dan kemampuan teknik produksi yang lebih baik.

h. Pendanaan untuk kebutuhan ekspansi usaha dari bank maupun lembaga non bank belum diupayakan dengan baik, tetapi telah direncanakan dan disiapkan.

i. Model kelompok usaha "Peugot Aceh" dapat dijadikaan sebagai model pengembangan wirausaha pemuda yang berbasis pemberdayaan masyakarat.

j. Kegiatan IbM ini telah mempu meningkatkan partisipasi dosen dan mahasiswa AMIK Indonesia dalam kegiatan pemberdayaan masyarakat. 
BAKTI BANUA : Jurnal Pengabdian Kepada Masyarakat

Volume 1 No. 1 Mei 2020

https://ejurnal.stimi-bjm.ac.id/index.php/BBJM/

\section{UCAPAN TERIMAKASIH}

Ucapan terima kasih sebesar-besarnya kepada LPPM AMIK Indonesia sebagai penyandang dana kegiatan pengabdian tidak lupa pula kepada Dosen-Dosen AMIK Indonesia, Staff Akademik beserta anggota pengabdian yang terdiri dari mahasiswa dan alumni AMIK Indonesia.

\section{DAFTAR PUSTAKA}

Alfaqi, M.Z., Habibi, M.M. and Rapita, D.D., 2017. Peran Pemuda Dalam Upaya Pencegahan Korupsi dan Implikasinya Terhadap Ketahanan Wilayah. Jurnal Ketahanan Nasional, 23(3), pp.320337.

Nursyamsu, R., 2018. Pelatihan Peningkatan Kapasitas Pemuda Dan Pembuatan Program Kerja Pada Organisasi Pemuda Desa Cibinuang, Kabupaten Kuningan. Empowerment: Jurnal Pengabdian Masyarakat, 1(02).

Mardiyati, R.H., 2018. Peran Pemuda Dalam Pembangunan Bangsa Perspektif Hadis. Journal of Hadith Studies, 1(2).

Wali, M., Akbar, R., Iqbal, T. and Al-Bahri, F.P., Development Of An Android-Based Tourism Guide (A Case Study: Sabang City, Indonesia). International Journal of Scientific and Technology Research, 8(11). pp.887-893.

Akbar, R. and Mukhtar, M., 2019. E-Tracer Study Based on Expert Systems (A Case Study at AMIK Indonesia). EPH-International Journal of Science And Engineering, 5(5), pp.12-17.

Fathun, L.M., Situmeang, N. and Rosdiana, H., 2019. PEMBERDAYAAN MASYARAKAT TERHADAP DAMPAK PEREDARAN NARKOTIKA DAN PERAN PEMUDA DALAM MEMINIMALISIR PEREDARAN NARKOTIKA DI KALANGAN REMAJA. BULETIN ILMIAH NAGARI MEMBANGUN, 2(4), pp.470-480.

Rizal, S., 2020. "PKM : Pemberdayaan Generasi Muda Melalui Enterpreneurship di Gampong Leuge Kecamatan Peureulak Kabupaten Aceh Timur", TRIDARMA: Pengabdian Kepada Masyarakat (PkM), 3(1, Mei), pp. 35-39.

Satoto, B.D. and Khotimah, B.K., 2019. Empowerment of the Talango Islands Community Sumenep Regency through digital printing and screen printing business. Berdikari: Jurnal Pengabdian Masyarakat Indonesia, 1(3), pp.118-124.

Indriati, D.S., 2017. Urgensi Wakaf Produktif Dalam Pembangunan Ekonomi Masyarakat. Jurnal Ilmiah Al-Syir'ah, 15(2).

Fonna, N., 2019. Pengembangan Revolusi Industri 4.0 dalam Berbagai Bidang. GUEPEDIA.

Shofiyah, S., 2018. Menumbuhkan Jiwa Enterpreneur Berbasis Syariah Di Kalangan Generasi Muda. Al-Musthofa: Journal of Sharia Economics, 1(2), pp.96-106.

Kurniawan, P., 2017. Pendidikan dan masa depan: Studi latar sosio kultural terhadap motivasi mahasiswa Bojonegoro di UIN Maulana Malik Ibrahim Malang (Doctoral dissertation, Universitas Islam Negeri Maulana Malik Ibrahim).

M AYIK SUGAMA, A.Y.I.K., 2019. EVALUASI PROGAM PENGEMBANGAN KEPEDULIAN DAN KEPELOPORAN PEMUDA DI DESA JATISABA TAHUN 2018 (Studi Eksploratif 
BAKTI BANUA : Jurnal Pengabdian Kepada Masyarakat

Volume 1 No. 1 Mei 2020

https://ejurnal.stimi-bjm.ac.id/index.php/BBJM/

Kualitatif Evaluasi progam pengembangan kepedulian dan kepeloporan Pemuda di Desa, Kec. Cilongok, kab. Banyumas, Provinsi jawa tengah tahun 2018).

Pradikto, S., Taufiq, M. and Istiqomah, L., 2017. PERSEPSI MASYARAKAT DI LINGKUNGAN INDUSTRI UNTUK MELANJUTKAN KE PERGURUAN TINGGI. Jurnal Ilmiah Edukasi \& Sosial, 5(1), pp.90-101.

Suharno, B., 2007. Langkah Jitu Memulai Bisnis dari Nol. Niaga Swadaya.

Mujiburrahman, M. ed., 2019. Technopreneurship Millennial: Technopreneurship Millennial (Vol. KITA Publisher.

Rizal, S., Wali, M., 2018. Perbankan Komputer : Teori dan Praktikum. Deepublish.

Akiel, A., 2017. EFEKTIVITAS PENDIDIKAN KEWIRAUSAHAAN DALAM MENINGKATKAN MINAT MAHASISWA TERHADAP DUNIA WIRAUSAHA (Studi kasus: Mahasiswa Universitas Indraprasta PGRI). JABE (Journal of Applied Business and Economic), 1(2), pp.92-105.

EVI, A., 2017. KARAKTERISTIK DAN DETERMINAN PENGANGGURAN USIA MUDA DI INDONESIA (Doctoral dissertation, Universitas Andalas).

Khairani, Z., Kamilah, F. and Soviyanti, E., 2018. PERAN PENDIDIKAN FORMAL DAN KONSEP DIRI TERHADAP POTENSI KEWIRAUSAHAAN PADA MAHASISWA. Jurnal Ilmiah Ekonomi dan Bisnis, 15(2), pp.139-149.

Dainuri, D., 2019. KONTRIBUSI PENDIDIKAN ENTREPRENEURSHIP: SUATU UPAYA KONSTRUKTIF MENUMBUHKAN JIWA WIRAUSAHA PADA MAHASISWA. Journal of Sharia Economics, 1(1), pp.1-13.

Bahruni, B. and Fathurrahmad, F., 2019. Analisis Trend Topik Pengembangan Rekayasa Perangkat Lunak dalam mendukung Strategi Kurikulum Perguruan Tinggi. Jurnal JTIK (Jurnal Teknologi Informasi dan Komunikasi), 3(2), pp.70-74.

Firdaus, N., 2018. Pengentasan kemiskinan melalui pendekatan kewirausahaan sosial. Jurnal ekonomi dan Pembangunan, 22(1), pp.55-67.

Sahban, M.A. and SE, M., 2018. Kolaborasi Pembangunan Ekonomi di Negara Berkembang (Vol. 1). SAH MEDIA..

Hodidjah, H., Rustono, W.S., Pranata, O.H. and Lidinillah, D.A.M., IbM KELOMPOK USAHA PEMUDA BIDANG KERAJINAN, SOUVENIR, SABLON DAN PERCETAKAN.

Syahputra, E. and NIM, S., 2017. Pengentasan Kemiskinan Melalui Hukum Sebagai Sarana Pemberdayaan CSR (Corporate Social Responsibility) Dalam Kegiatan Pertambangan Emas Di Tapanuli Selatan (Doctoral dissertation, Universitas Diponegoro).

Nasir, N. and Muhammad, S., 2017, October. DAMPAK INDUSTRI KREATIF DAN STRATEGI TERHADAP PENINGKATAN KESEJAHTERAAN MASYARAKAT DI KABUPATEN ACEH BESAR (STUDI PADA SUBSEKTOR INDUSTRI KERAJINAN DI KABUPATEN ACEH BESAR. In Prosiding Seminar Nasional USM (Vol. 1, No. 1) 
BAKTI BANUA : Jurnal Pengabdian Kepada Masyarakat

Volume 1 No. 1 Mei 2020

https://ejurnal.stimi-bjm.ac.id/index.php/BBJM/

Nasir, N. and Yuslinaini, Y., 2017. Analisis Pemetaan Industri Kreatif Subsektor Kerajinan Serta

Dampak Peningkatkan Kesejahteraan Masyarakat di Kabupaten Aceh Besar. Jurnal EMT KITA, 1(1), pp.12-17. 